Obras en el molino de la Mina de la villa de Alcalá de Guadaíra (1796-1820): informes de Cayetano Vélez, Manuel Cintora y José Echamoros

Fernando García Sánchez

Archivo General de Indias (España) 



\title{
Obras en el molino de la Mina de la villa de Alcalá de Guadaíra (1796-1820): informes de Cayetano Vélez, Manuel Cintora y José Echamoros
}

\section{Works in the Mine mill of the town of Alcalá of Guadaíra (1796-1820): reports made by Cayetano Vélez, Manuel Cintora and José Echamoros}

Fernando García Sánchez

Archivo General de Indias (España)

fgarcisanchez@hotmail.com

Fecha de recepción: 05 de junio de 2018

Fecha de aceptación: 20 de diciembre de 2019

\section{Resumen}

El objeto del presente estudio es dar a conocer las obras que se llevaron a cabo entre los años 1796 y 1820 en el Molino de la Mina (Alcalá de Guadaíra, Sevilla) y que consistieron en poner a funcionar una segunda piedra de moler. Finalidad que no se consiguió debido a los inconvenientes técnicos y de caudal del referido molino. Para ello se hicieron unos informes de las mencionadas obras en las que intervinieron Cayetano Vélez, Manuel Cintora y José Echamoros.

Palabras claves: Molino de la Mina (Alcalá de Guadaíra, Sevilla); Molinos hidráulicos; Vélez, Cayetano; Cintora, Manuel; Echamoros, José.

\begin{abstract}
The objective of the present study is to make known the works that were carried out between the years 1796 and 1820 in Mine Mill (Alcalá de Guadaíra, Seville) and which consisted in putting to work a second grinding stone. This purpose was not achieved due to the disadvantages technical and flow characteristics of said mill. For this purpose, reports were made of the mentioned works in which Cayetano Vélez, Manuel Cintora and José Echamoros.
\end{abstract}

Keywords: Mine Mill (Alcalá de Guadaíra, Seville); Hydraulic mills; Vélez, Cayetano; Cintora, Manuel; Echamoros, José. 


\section{INTRODUCGIÓN. EL MOLINO DE LA MINA: ORIGEN Y EX- PLOTACIÓN. DE UNA PROPIEDAD NOBILIARIA A UNA COM- PAÑÍA INGLESA DE AGUAS}

Desde época romana conocemos que la llegada del agua a Sevilla se realizaba a través de un acueducto conocido como los Caños de Carmona. La extracción, aprovechamiento y localización del agua subterránea está en el pueblo de Alcalá de Guadaíra y más concretamente en el manantial denominado la Mina de Santa Lucía. Este conjunto subterráneo conocido como el molino de la Mina suministraba el agua a Sevilla y desarrollaba la actividad propia de un molino harinero.

Después de la reconquista de la ciudad de Sevilla y con el posterior asentamiento de la nobleza en el siglo $\mathrm{XV}$, tenemos conocimiento por fuentes documentales que el dueño del molino de la Mina era Juan Fernández Mejías (Flores, 1833, p. 50), jurado y contador mayor de la ciudad de Sevilla. En el siglo XVII la propiedad del molino de la Mina pasó a Juan de Guzmán y Dávalos, mercader sevillano, que tuvo relaciones con las Juntas del Consulado (Vilar, 2016, pp. 175, 197), y estaba casado con Mariana de Santillán y Guzmán. Su hijo fue el primer marqués de la Mina, Pedro José de Guzmán Dávalos ${ }^{1}$ bautizado el jueves día 6 de octubre de 1650 en la iglesia sevillana de San Pedro y su padrino fue Bernardo de Valdés y Godoy (Álvarez, 2000, pp.143, 145) ${ }^{2}$, vecino de la collación de Santa María y una de las personas más influyentes del contexto económico y social de la ciudad. Esta propiedad nobiliaria fue pasando a lo largo de los siglos de dueño en dueño hasta 1765 en que Jaime Miguel Guzmán Dávalos y Spínola, segundo marqués de la Mina, muere sin sucesión. Entonces, el título pasó a su sobrino carnal, Pedro de la Cueva y Guzmán, duque de Alburquerque y tercer marqués de la Mina que lo ostentó solamente un año. Siguió conservándose el título en la Casa de Alburquerque durante los siglos XVIII y XIX hasta la separación del Marquesado de la Mina que se agregó al Ducado de Fernán Núñez.

Pedro José de Guzmán Dávalos tenía varios patronatos heredados de sus fundadores, Diego López Dávalos, condestable de Castilla y de su esposa Teresa Coronado, repartidos por la ciudad. Uno era el que estaba establecido en la iglesia de Omnium Sanctorum dedicado a obras pías y legos que consistía en dar una dote de 60 ducados a una doncella huérfana, como la dotación que se hizo a Marina Ruiz Díaz Maldonado $\mathrm{y}^{3}$ concedido dicho privilegio el 27 de diciembre de 1674. Otro patronato

1 Archivo Histórico de Nobleza. [en adelante], AHNOBLEZA. FERNANNUÑEZ, C. 218, D. 15.

2 Además de ejercer como comprador de oro y plata, al menos desde 1632, fue también un rico mercader, fuertemente vinculado a la Carrera de Indias. Valdés fue uno de los miembros más activos de la Hermandad de la Santa Caridad, y en gratitud por sus generosos donativos se le adjudicó el patronato de la Capilla Mayor del templo de San Jorge, permitiéndole reposar en ella a su muerte.

3 AHNOBLEZA. FERNANNUÑEZ, C. 1069, D. 1 (1-20). "En dotación del patronato, de los señores Diego López Dávalos, y doña Teresa Coronado su mujer nombró a doña Marina Ruis Maldonado hija de Alonso Ruis Marchena y de doña Francisca Vargas bautizada en la iglesia de 
era un juro que rentaba 34.121 maravedíes anuales en los derechos de almojarifazgos de Indias ${ }^{4}$. Además, Teresa Coronado tenía dispuesto en su testamento una renta anual de 200 ducados para el colegio Regina Angelorum ${ }^{5}$ de la ciudad de Sevilla.

Estos gastos sufragados con estas dotaciones económicas mantuvieron patronatos y capellanías que jugaron un papel muy importante en la salvación eterna del alma de estos nobles. De este modo, con la renta que generó el molino harinero de la Mina mantuvieron los dos patronatos vinculados a él y siempre estuvieron ligados a personas de la misma familia. Pero, a pesar de estas buenas rentas, este patronato tuvo que resolver numerosos pleitos contra personas que tomaron a renta el molino de la Mina, unos fueron por incumplimiento de los pagos y otros por las obligaciones que disponían una capellanía. Precisamente tuvo lugar un pleito en 1624 con relación a estos beneficios económicos, entre Mejías de Guzmán dueña del molino de la Mina y Antón Chinchorros por cierto dinero que le debía de las rentas:

Doña Maria Mesia [sic] de Juzman [sic] (...) dio poder a Lorenzo de Morales para que cobrase la renta del molino que dizen [sic] de la Mina que está dentro de la billa[sic]

Alcalá del Río que está sirviendo a su madre que viue en la parroquia de san Martín en una dote, de 60 ducados". Rodrigo de Aguilar y Mendoza hizo entrega como administrador del patronato a doña Marina los 60 ducados para ayudar a su casamiento, no obstante hubo que "verificar si esta doncella era pobre, si está en opinión de donçella honesta, de buena vida y fama, no ser mulata, morisca ni india, ni negra y que está sirviendo o haya servido en esta çiudad en casas honradas dos años por lo menos".

4 AHNOBLEZA. FERNANNUÑEZ, C.4, D. 40. "Francisco Ximenez de Miranda administrador que soy del patronato que fundaron Diego López Dabalos y doña Theresa Coronado su muger y en virtud del poder que los patronos me otorgaron(...) Antonio Martinez de Herrera tesorero general de las rentas del almoxarifazgo de Indias(...) cinco mil y seiscientos y ochenta y siete maravedies que importa la mitad de la rentta del tercio primero de fin de abril del año pasado de mil seiscientos y sesenta y dos de los treinta y quatro mil ciento y beinte y uno maravedies de juro y renta en cada un año situado en las del dicho almoxarifazgo de Indias..."

5 AHNOBLEZA. FERNANNUÑEZ, C. 808, D. 1 (4). "Damián Camacho mayordomo del patronato que fundaron los señores Diego López de Dabalos y doña Theresa de Coronado su muger para el convento de Rexina a quien su poder o causa ubiere duzientos ducados los cuales mandamos librar por la causa y razón contenida en la çertificacion de otras que son los que los señores dejo los fundadores en cada un año a el dicho convento para la sacristía y otras cosas como se refieren en la dicha fundación..." Los doscientos ducados se gastaban en el año de 1638 de esta forma, "primeramente nobenta ducados en nuebe fiestas con missa y sermón cada una que dejo dotada la dicha señora por su alma y la de su marido(...)se gasta cinquenta ducados en el médico del convento, doctor Mancebo 24 ducados, a Tiberio cirujano del convento 8 ducados, lo restante en gallinas, viscochos, dulces, medicinas, botica y demás cosas necesarias para la enfermería(...)los sesenta se han gastado en la sacristía en las cosas siguientes quatro albos de ruan que costaron veinte ducados, un paño de hombros de tela y paño de calix de lo mismo con puntas de oro y plata, y otro paño de tafetán anteado para el mismo efecto que todo costo dozientos reales y lo demás que resta para cumplir la dicha cantidad de los 60 ducados y de un terno negro de terciopelo con faldones de brocatel y pasamanos de oro que quedo de resto del año pasado". 
de Alcalá de Guadayra[sic] que lo a tenido y tiene en arrendamiento Anton Chinyorros [sic] (...) de quattro [sic] mil reales en cada un año ${ }^{6}$.

También, el marqués de la Mina tuvo que someterse a un auto por parte de los curas de la iglesia del Sagrario de la ciudad de Sevilla en 1734 contra sus bienes y sobre la cobranza de 3 arrobas de harina anuales que se pagaban a dichos curas sobre el molino de la Mina y, cuyo memorial fundó el padre fray Juan Fernández Mejías religioso de Santa María de las Cuevas en 1467. Así:

Por el qual [sic] dicho codizilo [sic] nombró a los tres curas del Sagrario por visitadores de la capilla de san Lucas sita en la iglesia parroquial del señor san Andrés de esta dicha ciudad (...) les asigno las dichas 30 arrobas de harina anuales, para que las partiesen entre si, dejando cargada y situada esta memoria sobre el dicho molino de la Mina, en termino de Alcalá de Guadaíra ${ }^{7}$.

Por este mismo tributo pagaba el año 1892 la administración del Estado de Fernán-Núñez en Sevilla a la capellanía fundada por fray Juan Fernández Mejías a la iglesia parroquial de San Andrés la cantidad de 332 reales de vellón ${ }^{8}$.

La explotación de este molino de la Mina generó grandes beneficios y sus dueños solían arrendarlo por periodos cortos de años. La posesión de estos molinos tuvo gran prestigio social en la nobleza por el valor económico que generaba. Este molino estuvo en funcionamiento hasta finales del siglo XIX, a partir de entonces, se fue abandonando la molienda como el propio edificio. Después, de haberse mantenido el molino de la Mina durante varias generaciones en el marquesado de la Mina, el día 16 de octubre de 1901, se firmaba la escritura de venta del molino de la Mina en Madrid. Entre los firmantes se encontraban el abogado Ramón Grau y Nadal como mandatario de la excelentísima señora duquesa de Fernán-Núñez y Pedro Gauna y García de profesión procurador en representación de la Sociedad "The Seville Water Works Company Limited" ante el notario del ilustre colegio de Madrid Teolindo Soto y Barro. Entre las cláusulas de la escritura se decía lo siguiente:

Primero: Que su mandante la Excelentísima señora doña María del Pilar Loreto Osorio y Gutiérrez de los Ríos, duquesa de Fernán-Núñez, es dueña, por herencia de su padre el señor don Felipe María Osorio y de la Cueva, Conde de Cervellón, de la finca que a continuación se describe (...) un molino harinero, sin número, llamado

6 ARCHIVO HISTÓRICO PROVINCIAL DE SEVILLA. AHPS. Sig. 29225, leg. 4, fol. 9 r-v.

7 AHNOBLEZA. FERNANNUÑEZ, C. 69, D. 17.

8 AHNOBLEZA. FERNANNUÑEZ, C. 1301, D. 12. "Como capellán propio que soy de la instituida en la yglesia Parroquial de San Andrés de la ciudad de Sevilla por fray Juan Fernandez de Mejias; he recibido del Sr. Joaquin Mariño como administrador del Excmo. Sr. Duque de Fernan-Nuñez la cantidad de trescientos treinta y dos reales de vellón por un año de tributo vencido el día treinta y uno de diciembre del año proximo pasado de mil ochocientos noventa y uno, quedando abonadas las contribuciones, Sevilla 16 de febrero de 1892. [Firma] Manuel Vejarano y Cerón”. 
de la Mina, movido por las aguas del acueducto de Santa Lucía, sito en la calle de Cánovas del Castillo, antes de la Mina, de la villa de Alcalá de Guadaíra (...) que esta finca es libre de toda carga, deuda y responsabilidad, salvo dos censos, el uno, de veinte mil cuatrocientos reales, de capital a favor de la capellanía fundada por don Francisco Díaz en Omnium Sanctorum, y el otro, de once mil sesenta y seis reales, también de capital a favor de la que en San Andrés fundó F. Juan Fernández. Que, en nombre de la excelentísima señora doña María del Pilar Loreto Osorio y Gutiérrez de los Ríos, Duquesa de Fernán-Núñez, y llevando a efecto lo entre ambos comparecientes convenido, vende a la sociedad "The Seville Water Works Company Limited" el molino descrito en la cláusula primera de esta escritura, y cuanto al mismo pertenece o de él es accesorio, por el precio de ocho mil quinientas sesenta y seis pesetas, sesenta y siete céntimos, las cuales recibe en este acto, a mi presencia, en efectivo y para la expresada Señora, de mano de don Pedro Gauna, mandatario de la repetida Sociedad; cuyo precio han fijado ambos señores otorgantes partiendo del supuesto de estimar la totalidad del inmueble en doce mil quinientas pesetas y de rebajar de esta cantidad tres mil novecientas treinta y tres pesetas, treinta y tres céntimos, en que se evaluaron, para deducirlas, los dos gravámenes censales relacionados en la cláusula anterior?

Definitivamente, el molino harinero de la Mina dejó de tener aquella actividad molinera tan intensa y quedó en desuso con su venta. Del mismo modo que otros molinos con la llegada de una nueva energía, la electricidad, que dio paso a nuevos molinos movidos por esta novedosa fuente energética. A pesar de todo, este molino no dejó de abastecer de agua a Sevilla hasta mediados del siglo XX.

\section{EL MOLINO DE LA MINA A FINES DEL XVIII Y COMIENZOS DEL XIX. AMPLIAGIÓN DE SU GAPACIDAD PRODUCTIVA. EL CONFLICTO GON FRANGISCO DE BRUNA}

Es entre los siglos XVI y XVII cuando en estos molinos harineros se van introduciendo algunas mejoras en la geometría de los álabes del rodezno. Estas modificaciones mecánicas fueron diseñadas para minimizar las pérdidas de energía por el choque del agua, logrando dar un mayor empuje a la rueda y obteniéndose mayores beneficios económicos. Los cambios en las instalaciones molineras se produjeron a partir del siglo XVII con la demanda y el aumento del consumo de harina por las necesidades humanas del abastecimiento de la ciudad de Sevilla (Bernal, 2003, pp. 145, 147). Después, los nuevos avances del siglo XIX trajeron la sustitución de la rueda de rodezno por las turbinas hidráulicas de metal. A finales del siglo XVIII se va iniciando el cambio de mentalidad preindustrial basado en la obtención de un mayor rendimiento y aprovechamiento de los recursos. Asimismo, desde tiempo inmemorial el hombre ha tratado de controlar y utilizar no sólo el agua

9 AHNOBLEZA. FERNANNUÑEZ, C. 66, D. 3. 
de los ríos y manantiales para uso primarios como el consumo humano, dar de beber a los animales y regar los cultivos, sino también la energía hidráulica que contiene para usos secundarios y terciarios (López, 2006, pp. 59-60). Por todo ello, las obras efectuadas por Miguel de la Cueva ${ }^{10}$, duque de Alburquerque, en el molino de la Mina en 1796 no tenían otra intención que poner en funcionamiento una segunda piedra o máquina para la molienda del trigo y obtener una mayor rentabilidad económica.

Al mismo tiempo, la existencia de los molinos sobre los Caños generaba muchísimos conflictos con la principal vocación de abasto urbano del acueducto y estos problemas se fueron agravando al aumentar las posibilidades de los molineros para regular el caudal (Fernández, 2011, p. 121). Las inquietudes de estos molineros no era otra que aprovecharse del emisario de agua para obtener mayores beneficios económicos. La vega de los Alcores estaba en un lugar privilegiado por ser la principal zona de transformación agroindustrial y por la proximidad a un marco geográfico de abundantes manantiales y afluentes que fueron un factor decisivo para la obtención de la energía y disponibilidades hídricas para mover molinos. Además, la disponibilidad de energía hidráulica fue la que consagró la especialización harinera-panadera de Alcalá en detrimento de otras localidades circunvecinas, como Carmona, Utrera, Jerez etc., pese a contar éstas con mayores disponibilidades de recursos cerealistas (Bernal, 2003, p. 60).

Hay un dato muy importante sobre este molino que conocemos por fuente bibliográfica y da pie a nuestro trabajo. Antes de acometerse las reformas, el molino poseía en 1796 un solo cubo y una sola piedra para moler. Este detalle se menciona en la oración inaugural que hizo el doctor Francisco de Buendía y Ponce el día 24 de octubre de 1765 y decía entre otras cosas: "La más famosa es la que llaman la mina [...] se ignora su origen y principio, pero son distintas aguas y de diferentes naturaleza; se juntan estas dos en un cono embudo o cubo y muele una piedra trigo: y cayendo se juntan con la de la Mina principal o general acueducto" (Flores, 1833, pp. 49-50).

Miguel de la Cueva ejecutó unas obras de ampliación en el molino para obtener mayores rendimientos en 1796 que modificaron el cauce y caudal que abastecía de agua a la ciudad de Sevilla. Los encargados de los arreglos fueron los maestros alarifes, Francisco del Castillo de Sevilla y Cristóbal de la Rosa vecino de Alcalá de Guadaíra, expertos en la ejecución de toda obra y construcción de molinos de agua. Ellos realizaron las obras para poner en funcionamiento una segunda máquina de moler y declararon por carta al apoderado del duque lo que había sucedido posteriormente:

Y teniendo acomodadas, y dispuestas las corrientes de las aguas que había, y con nuestras operaciones se han aumentado en el referido molino, para que este moliese en términos

10 Don Miguel de la Cueva era dueño del patronato de la capilla y retablo de la parroquia de Omnium Sanctorum de Sevilla, a él se debe la realización del nuevo retablo de estuco (Ros, 2000, pp. 153-172). 
muy bentajosos [sic] y seguro que hasta aquí, y descendiendo esta agua para las minas que las conducen al referido molino, aún cañón que lleba [sic] su corriente a la cañería, para la que transitan las aguas que ban [sic] para los Caños de Carmona a la ciudad de Sevilla, muy lejos de perjudicar esta agua en su corriente, y caudal, con las expresadas nuestras operaciones, se han aumentado en beneficio, y utilidad, de la misma cañería, y hallándose la obra del expedido molino próxima a concluirse, ha ocurrido la inesperada nobedad [sic] de que en el día de ayer, se presentó el señor don Francisco de Bruna juez pribatibo [sic] de los Reales Alcázares, y a quien por esta comisión pertenece la inspección de cañerías, y aguas de la expresada ciudad de Sevilla [...]/1v, proveyó en aquel acto, un auto mandándonos cesar inmediatamente en la practica de la manifestada obra del molino, bajo la pena de quatro [sic] años de presidio, y al mismo tiempo mandó romper, y desbaratar barias [sic] partes de los sitios por donde transitaban, y corrían las aguas para el objeto de la molienda, y haviendolos [sic] rebajado en disposición que jamás han estado, ha benido [sic] a quedar el peso, y corriente de aguas en termino que no pueden absolutamente tener uso las dos piedras del molino ${ }^{11}$.

Desde fecha muy remota, las aguas de los Caños de Carmona han pertenecidos al Real Patrimonio de la Corona que usufructuaba los beneficios. El administrador de los Reales Alcázares era el encargado de la jurisdicción, mientras el Ayuntamiento atendía a la vigilancia, control y mantenimiento del servicio viéndose forzado a invertir en muchas ocasiones grandes cantidades de dinero en obras de infraestructura (Aparicio et al., 1990, p. 147). Francisco de Bruna, Alcaide de los Reales Alcázares, enterado de las obras que se habían llevado a cabo en el molino de la Mina se personó e inspeccionó las cañerías. Éste aplicó todo su poder para restablecer al estado primigenio las aguas de dicho molino y no tuvo temor alguno en mandar destruir todo lo que se había construido para el funcionamiento conjunto de las dos ruedas de moler. Por la declaración de ambos alarifes podemos apreciar el carácter soberbio y arrogante de este personaje tan singular. El Alcaide, Francisco de Bruna (Aguilar, 2003, p. 22; López-Vidriero, 1999, pp. 14, 40), era la máxima autoridad en el abastecimiento de agua a Sevilla y en extremo celoso del principio de autoridad contra todo género de abusos y de excesos. Tenía la jurisdicción privativa también para juzgar todo lo relativo a las aguas de los Caños y podía visitarlo y castigar a los usurpadores, estando obligado a vigilar que nadie invadiese el espacio anexo a ellos (Fernández, 2011, pp. 190, 192). Francisco López de Bruna y Ahumada marca el límite entre el Antiguo Régimen y el siglo XIX en la Alcaidía del Alcázar en la que se va a producir la militarización del cargo, porque a partir de ahora todos sus titulares serán en adelante militares (Márquez, 2010, pp. 41, 59). Además, esta persona resalta del conjunto de los Tenientes de Alcaide de los Reales Alcázares por el propio peso que su actividad tuvo en múltiples ámbitos de la vida judicial y cultural de la época. Desde esta posición privilegiada en el panorama de la ciudad, Bruna desarrolló su pasión por las antigüedades y las artes que lo convierten en arqueólogo, anticuario,

11 AHNOBLEZA. FERNANNUÑEZ, C. 69, D. 17. fol. 1v-2r. 
coleccionista, bibliófilo y en general en un auténtico erudito ilustrado. Bruna será el protector de la Escuela de las Tres Nobles Artes de la ciudad y dirigirá desde su posición pública eminente el camino de esta institución artística. Además con respecto a la profesión del arquitecto en su tiempo, Bruna asume las premisas del movimiento académico en torno a su formación (Ollero, 2004, pp. 61, 64, 70). Un ejemplo de su implicación en este ambiente cultural de la ciudad fue la solicitud que presentó Lucas Cintora en la Real Audiencia de Sevilla para ser honrado en la enseñanza pública de las matemáticas como Director de Arquitectura, en la exposición de sus méritos decía que: "Con estos tales cuales méritos de que podrán informar si fuere necesario, al señor don Francisco de Bruna, que está más enterados que otros en el interior de la Academia" (Ollero, 2012, pp. 27, 42). En efecto, en 1765 este granadino altivo como lo describe el profesor Aguilar Piñal se convertía en Teniente de Alcaide cargo que ejercería hasta su muerte en 1807. Fue dueño absoluto de la justicia sevillana, sensible a las ideas ilustradas por su fidelidad al régimen de los Borbones y por sus buenas relaciones con la sociedad estamental establecida, logró hacerse con las riendas de la vida política, económica y cultural de Sevilla en la segunda mitad del siglo XVIII. Por último, esta decisión del Alcaide del Alcázar de cerrar el molino de la Mina, los acontecimientos históricos posteriores como la guerra de la Independencia contra los franceses y la epidemia de peste amarilla que asoló la capital y la provincia provocaron que se suspendiera temporalmente la actividad molinera.

\section{PUESTA EN MARCHA DEL MOLINO Y PLEITO. LICENGIAS E INFORMES: CAYETANO VÉLEZ, MANUEL GINTORA Y JOSÉ ECHAMOROS}

Como he manifestado anteriormente el molino de la Mina quedó destruido y estuvo inactivo, desde septiembre de 1796 al 7 de marzo de 1814, hasta que se arrendó a Juan Calzado por un periodo de nueve años desde el mes de junio de este año. Evidentemente, el compromiso contraído quedaba aclarado en las escrituras con las obligaciones y condiciones de dicho contrato. Decía entre otras cosas:

Quedando de cargo del dicho don Juan Calzado enteramente toda la operación, y obra que se necesite hacer, y practicar para el uso y ejercicio del molino con sujeción a lo decretado sobre el particular por dicho excelentísimo Ayuntamiento [...] podrá enviar cada y cuando que lo tenga por conveniente peritos e inteligentes que reconozcan el dicho molino y su sitio para ver, si esta corriente y reparado y en el caso de que así no lo encuentren con testimonio de la tal visita se ha de poder demandar ejecutivamente a el don Juan Calzado ${ }^{12}$.

12 AHNOBLEZA. FERNANNUÑEZ, C. 2183, D. 2. 
Calzado tuvo que pedir una licencia de obra para la puesta en marcha del molino por medio de una instancia al secretario del Ayuntamiento de Sevilla, y que contenía lo siguiente:

D. Juan García de Neyra del Consejo de su majestad, su secretario honorario, y en ejercicio del excelentísimo Ayuntamiento Constitucional de Sevilla: Certifico: que [Juan Calzado] teniendo acordado con el dueño del sitio del molino nombrado de la Mina en la villa de Alcalá de Guadayra [sic] en arrendamiento de esta finca [...] solicita ejecutarlo en términos de que jamás pueda decirse que infiere perjuicio al transito de las aguas que por dicho sitio corren a esta población $[\ldots]$ y que el arquitecto mayor reconociese el molino e informase lo que se le ofreciera, quien a su consecuencia practicó la dicha diligencia, y dio el informe ${ }^{13}$.

Pasado unos meses, el Cabildo de la ciudad de Sevilla acordó que se le diera la licencia de obra al interesado y vista todas las diligencias con el acuerdo de conformidad se le hizo saber que ejecutara la obra conforme al proyecto que emitió el arquitecto Cayetano Vélez, el 6 de febrero de 1814, en el que decía:

En el que se trataba según a parece de dha [sic] obra, colocar dos piedras con objeto de elevar las aguas para que su impulso violento fuese el agente de un movimiento continuo cuyo plan no debe realizarse por los graves perjuicios que resultarían en el retroceso y detención de las corrientes, lo que no tienen el menor inconveniente es la colocación de una sola piedra ${ }^{14}$.

Estas licencias de obras aparecerán desde 1789 y se generalizaran como acto recurrente en las nuevas intervenciones sobre la arquitectura civil desde 1801 (Ollero, 2015 , pp. 215, 257). Por lo tanto, en un principio con su licencia y conforme a las directrices técnicas de Vélez no hubo problemas para que Juan Calzado ejecutara las obras y pusiera en marcha una sola piedra. Una vez pasada la inspección, Calzado realizó los añadidos necesarios para poner en funcionamiento una segunda piedra del molino como se hizo en 1796, probablemente, para que funcionaran alternativamente. Con el paso de unos años, Juan Domínguez, Teniente Alcaide de los Reales Alcázares de Sevilla, proveyó un auto para que el Alguacil mayor de Palacio hiciese un reconocimiento el 10 de agosto de 1818 del recorrido de las aguas que llegaban desde Alcalá de Guadaíra a Sevilla y expusiera por escrito los abusos que advirtiese. El alguacil mayor Pedro Tenllado reconoció el molino de la Mina y de su examen dio la información siguiente:

Con noticia que había tenido de que en el molino nombrado de la Mina se había sentado una piedra para moler, además de la que tenía, se dirigió a él, y en efecto encontró ser

13 AHNOBLEZA. FERNANNUÑEZ, C. 2183, D. 2.

14 AHNOBLEZA. FERNANNUÑEZ, C. 1695, D. 9, fol. 33 v. 
cierto, $[\ldots]$ pero que a pesar de ello le quedaba la duda si el indicado pretil podía ser perjudicial, lo que correspondía conocer de facultativos ${ }^{15}$.

Estos abusos sobre los caños de Carmona se hacían notar más cuando la llegada de agua disminuía de caudal en la ciudad de Sevilla. Por ejemplo, cuando Cayetano Vélez fue requerido el 12 de agosto de 1813 para informar al Cabildo sobre el caudal de agua de los Caños de Carmona que se había reducido considerablemente debido a la suciedad de la mina y el mal estado de los salideros, aconsejando un guarda para que vigilase que los dueños de los molinos no colocasen tablones para interrumpir y derivar el curso de las aguas (Baena, 2015, p. 230).

Esta segunda piedra de moler generó dudas y se mandó inspeccionar el molino de la Mina con otra visita general en la que asistieron el alcalde alarife del Alcázar Manuel Cintora y el maestro fontanero José Arzúa. Ambos fueron al reconocimiento del molino y tuvieron en cuenta las declaraciones vertidas por el maestro José Antonio de la Rosa que asistió como alarife de las obras que se llevaron a cabo en el molino. De todo ello se entregó un auto de esta inspección que es el siguiente:

De la diligencia de reconocimiento de la obra ejecutada en el molino nombrado de la Mina, y de las declaraciones del arquitecto don Manuel Zintora [sic], y la que antecede del maestro alarife José Antonio de la Rosa, y al perjuicio que con la propia obra se causa a la corriente de las aguas, en grave perjuicio del público de dicha ciudad, y del Real Palacio [...] debía de mandar y mando que inmediatamente se demuela, y deshaga dicha obra ${ }^{16}$.

José Arzúa fue un reputado fontanero de la ciudad de Sevilla. En 1811 la fábrica de la Catedral de Sevilla pagó 174.284 maravedis a Martín Rodríguez, maestro aparejador de la santa iglesia, para que abonase al maestro fontanero José Arzúa la nueva cañería que había construido desde la huerta del Retiro hasta el arca del Patio de Banderas para poder llevar el agua a la Catedral (Baena, 2015, p. 228). De Manuel Cintora sabemos que era hijo primogénito de Lucas Cintora y de su primera mujer Catalina Díaz, y que sustituyó a su padre como maestro mayor de los Reales Alcázares a su muerte en 1800 (Ollero, 2004, 451).

Ante esta contrariedad, Juan Calzado tuvo que volver a realizar los trámites para que le dieran las licencias y reintegrar el molino al estado primigenio en que estaba según la práctica y costumbre. Entonces volvió a presentar un escrito, el 19 de septiembre de 1818, pasando el expediente al fiscal quien tomando los autos los devolvió por escrito el 23 de diciembre de 1818 asesorando lo siguiente:

Mandando se reconociese el sitio de la disputa por peritos que las partes nombrasen los que declarasen el modo de ejecutarse la obra en el molino de la Mina en términos que

15 AHNOBLEZA. FERNANNUÑEZ, C. 2183, D. 2.

16 AHNOBLEZA. FERNANNUÑEZ, C. 2183, D. 2. 
no se causase retroceso alguno a las aguas, ni se invirtiera su corriente, sino que tuviera su fluidez total continua, sin remanso excepto en el cubo de mampostería, que fuese necesario fabricar,(...) nombrados por las partes los arquitectos don Cayetano Vélez y don Manuel Zintora [sic] cumplieron sus encargos levantando el plano y dando sus declaraciones que unidas a los autos volvieron al fiscal ${ }^{17}$.

Según establecían las Ordenanzas de la ciudad, una de las principales atribuciones del Alcaide del Alcázar consistía en ejercer conjuntamente con el Asistente el control sobre el caudal y distribución del agua que desde Alcalá de Guadaíra entraba por los caños de Carmona hasta el Alcázar para su posterior canalización (Márquez, 2010, p. 97). Para tal fin se personaron en el molino de la Mina, Cayetano Vélez como arquitecto titular del Ayuntamiento de Sevilla y Manuel Cintora maestro mayor de los Reales Alcázares y maestro de obras de la Real Audiencia de Sevilla he hicieron un informe y el plano de las obras. Éstos fueron más concluyentes en sus declaraciones:

Don Cayetano Vélez arquitecto de la Real Academia de san Fernando, Mayor Titular por su Majestad del excelentísimo ayuntamiento de esta capital, socio de la Real Sociedad, conservador por Real orden de las Antigüedades de Itálica, y Académico de Honor y mérito de la Imperial academia de san Lucas de Roma, de conformidad con don Manuel Zintora [sic] maestro Mayor de los Reales Alcázares, y alarife del Público. Certificamos; que a consecuencia de providencia del señor general Gobernador de dichos Reales Alcázares, practicamos un prolijo reconocimiento de la mina de Alcalá de Guadayra [sic] en cuyo punto se reúnen los ramales de las aguas, que nacen en las montañas de este nombre, y cuyo subterráneo de la base por donde se dirigen a Sevilla, a el qual [sic] acompaña el adjunto plano, que geométricamente marca la expresada mina, donde se indican las bocas y entradas de las aguas, y sus salidas con dirección a la capital, y siendo evidente, que desde los puntos del nacimiento general, y demás remanentes en toda su longitud hasta su salida (A), en el plano de la entrada a el acueducto (B), que viene a Sevilla hay mas de sesenta pies de nivel, por cuyo motivo no se debe estar a la declaración, folio (12), dada por el maestro de la Real Alcázar, Manuel Zintora, [sic] por que este facultativo no tubo[sic] tiempo en aquel reconocimiento ni instrumento alguno para las operaciones necesarias, y no teniendo el más mínimo conocimiento del sitio por ser la primera vez que lo pisaba, se vio obligado extender sin su parecer, con / $2 \mathrm{v}$. arreglo a lo que oía de unos y otros, pero ahora últimamente habiendo ido acompañado de don Cayetano Vélez, arquitecto del excelentísimo ayuntamiento de la ciudad, quien ha hecho varias nivelaciones, y levantado plano del dicho terreno en distintas ocasiones como se presenta el adjunto para mayor inteligencia de las operaciones hechas por el mismo arquitecto y Zintora, [sic] decimos de conformidad que con arreglo a los sesenta pies de nivel, que le han notado no nos queda dificultad en que el muro el muro $\mathrm{n}^{0} 7$, quede en la altura de veinte pulgadas, y por este medio pueden sin el menor perjuicio volver a trabajar las piedras, que le indican en el plano con los números 1 y 2 , sin que

17 AHNOBLEZA. FERNANNUÑEZ, C. 2183, D. 2. 
por este haya el menor retroceso en las aguas ni la más mínima degradación en su caudal y pues solo se reduce a que las canales, A-A, que antes se dirigían por los números 3 y 4, hagan punto de reunión en el número 5 , y le dirijan por el número 6 , a la boca $\mathrm{B}$, de la salida general a esto está reducida la inteligencia firme, y verdadera institución de las piedras de las quales [sic] solo una muele constantemente debiendo servir la otra para picarla y prepararla sin que en esta alternativa se deba entender mas que el movimiento de una sola piedra, para lo qual [sic] es correspondiente potencia del caudal de las aguas, debiéndose considerar no resulta ni imaginario perjuicio del caudal de aguas, que producen las montañas y se dirigen a esta capital para su abasto, prueba de eso / 3r. que en el examen que hicimos el día de nuestra visita del repartimiento general, que está en la puerta de Carmona y la mayor parte de los molinos, que hay en su transito, hasta el descubrimiento que está en la Hacienda de la Red, no se había notado la más mínima alteración en las aguas, sin embargo de estar el muro $\mathrm{n}^{\mathrm{0}} 7$, en parte destruido en todo el tiempo que media desde el 18 de agosto de 1818, día que fue la visita general con vuestra señoría hasta el 19 de enero de 1819, que la hizo el arquitecto don Cayetano Vélez con Zintora, [sic] que es quanto [sic] se puede informar a vuestra señoría en virtud de lo mandado. Sevilla 19 de enero de 1819. Manuel Zintora [sic] ${ }^{18}$.

Cayetano Vélezy Cintora elaboraron un informe y un plano detallado de las bocas de los manantiales y efectuaron las medidas de las nivelaciones del terreno. Estos dos facultativos sólo determinaron una medida en el informe, las veinte pulgadas que convendría que tuviera el muro de la represa y un breve detalle técnico, solo debería funcionar una sola piedra. En este primer informe se limitaron a dar una solución rápida a los problemas planteados en las obras del molino. Tal vez, no fue acertada su solución dando mayor interés a la llegada de agua a Sevilla que a la comprobación del funcionamiento de las máquinas del molino. Vélez deja claro que su trabajo se limita a la supervisión de las obras y acude más como consultor que como ejecutor, representando el modelo de arquitecto ilustrado. Conocemos que, desde 1810 hasta 1812 con la ocupación francesa, Vélez estuvo interviniendo en multitud de obras en la ciudad de Sevilla en calidad de arquitecto mayor del cabildo municipal. Es el caso, de su intervención en la casa de los Cavaleri para el General Gazan (Ollero, 2002, pp. 189, 199). Asimismo, Cayetano Vélez diseñó en mayo de 1816 dos proyectos de adorno efímero de las Casas Consistoriales, uno correspondiente al ornato de la galería de dos alturas del edificio, y un segundo destinado a levantarse en el frente del cabildo hacia el sur, que afrontaba hacia la calle Génova (Ollero, 2016, pp. 387, 400). En cuanto a Manuel Cintora sabemos que era un personaje conocido en el mundo artístico sevillano. Ocupa el puesto de Alcalde Alarife en $1812 \mathrm{y}$, entre otras actuaciones realiza múltiples denuncias sobre el estado de algunos edificios. En 1813 elabora un informe sobre las obras necesarias para la reparación del Alcázar (Baena, 2015, pp. 526-527). Desde 1805 a 1813 estuvo realizando obras de envergadura en el Real Palacio de los Reales Alcázares (Ollero, 2004, p. 451).

18 AHNOBLEZA. FERNANNUÑEZ, C. 69, D. 17. fol. 2v-3v. 
A continuación de esta visita, John Downie, caballero de la Real y distinguida Orden Española de Carlos III, Mariscal de Campo de los Reales Ejércitos y Teniente de Alcaide de los Reales Alcázares de Sevilla, habiendo visto los autos contra Juan Calzado y lo expuesto por el arquitecto Cayetano Vélez y el maestro mayor de obras de los Reales Alcázares Manuel Cintora, mandó el 21 de abril de 1819 que inmediatamente se procediera a la ejecución de la obra del molino de la Mina. Calzado realizó las oportunas obras ajustándose al informe emitido por ambos y se dio cuenta como sigue:

Se proceda a la ejecución de la obra que necesite el molino de la Mina de la Villa de Alcalá de Guadayra [sic] en términos que no se cause retroceso alguno a las aguas, ni se invierta su corriente, sino que tengan su fluidez, y curso rápido sin remanso excepto en el cubo de mampostería, que sea necesario fabricar bajo la dirección de los mismos inteligentes y de su responsabilidad ${ }^{19}$.

No obstante, se volvió a emitir otro nuevo informe antes de emprender las obras y se solicitó a Cayetano Vélez y Manuel Cintora que fueran de nuevo al molino de la Mina. En él se daban las instrucciones precisas de los reparos necesarios y la puesta en funcionamiento de una sola piedra de moler. Ambos decían:

En virtud de la última resolución que por providencia del señor general Alcaide de los Reales Alcázares se nos ha intimado por el señor escrivano [sic] de Cámara don Francisco Xavier [sic] Solano para que bajo nuestra responsabilidad se practiquen las obras de la colocación de las dos piedras que formaran el uso constante de una sola en el molino de la Mina de Alcalá de Guadayra [sic] y para que estas operaciones se realisen [sic] conforme esta declarado en el expediente. El maestro facultativo de albañilería que elija don Juan Calzado para aquellas operaciones puede proceder a dar principio bajo las siguientes reglas. El muro que se construlla [sic] para reunir los dos ramales que descienden de las montañas será nibelado [sic] exactamente con el resto del antiguo parapeto que allí existe, los suelos procedentes de las dos bocas por donde las aguas se reúnen en el punto de las piedras que descendentemente y sin el menor retroceso cursas al aqueducto [sic] inferior dirigiendo a Sevilla. Estas son las obras que bajo reglas de toda solidez deben practicarse con algunos cortos reparos en la mina para hacer susceptible el uso de este molino en beneficio del público y sin el menor perjuicio del curso de las corrientes, baxo [sic] las precisa qualidad [sic] que tan luego como se verifique su conclusión dado aviso por don Juan Calzado se repasará a su reconocimiento, de cuyo estado se pondrá certificación a la letra para satisfacer el Tribunal según su mandato para uso y seguridad del interesado y permanencia de aquel establecimiento evitando con estas formalidades el menor resultado de nulidad. Sevilla 22 de mayo de 1819. Cayetano Vélez y Manuel Zintora [sic ${ }^{20}$.

19 AHNOBLEZA. FERNANNUÑEZ, C. 2183, D. 2.

20 AHNOBLEZA. FERNANNUÑEZ, C. 69, D. 17. fol. 4r. 
A pesar de este informe, Juan Calzado prosiguió aportando documentos al fiscal en el que exponía que había realizado las obras conforme a las directrices de José Antonio de la Rosa experto en obras de molino y que se podía hacer un uso alternativo de las dos piedras. En realidad lo que trataba Calzado era crear dudas en las autoridades sobre el funcionamiento de ambas piedras, y ante esta tenacidad, el fiscal de estos autos mandó el 29 de diciembre de 1819 al arquitecto del Ayuntamiento de Sevilla José Echamoros que habiendo aceptado y jurado su encargo proveyó una declaración y evaluación de las obras. En este informe dijo lo siguiente:

Don José Echamoros arquitecto y maestro mayor titular de esta ciudad, socio de mérito en la Real de las tres Nobles Artes establecida en mi, maestro mayor de fortificaciones, y reales obras militares de esta plaza por su Majestad gozando de las mismas preeminencias y regalías que los arquitectos de las Reales Academias de san Fernando y san Carlos. Consecuente con la comisión, que se le ha conferido, por el señor teniente de Alcayde [sic] de los Reales Alcázares de esta dicha ciudad, con acuerdo del señor don Juan Pedro Morales, oidor de esta Real Audiencia, y asesor por su Majestad en dicho Real Palacio, paso a la villa de Alcalá de Guadayra, [sic] al reconocimiento de la obra ejecutada en el molino, que nombran de la Mina, que esta situado en la calle Real de dicha población, según y en los términos pedidos por el Fiscal de dicho Real Palacio, en su dictamen, que precede y estando en dicha población, y reconocido el citado molino de la Mina del agua, que se dirige a esta ciudad para su abasto público, por la denuncia que de lo obrado últimamente en él se había hecho folio 12 y 13 de los autos formados a este efecto, quando [sic] se hizo la visita general de todo el citado aqueducto, [sic] folio 10 y 11, dimanada del parte que había dado anteriormente el Alguacil Mayor de dicho real sitio folio 2 y 3 , teniendo presente el plano y declaración de los folios 65 y 66, dictamen fiscal folio 69 , y demás declaraciones y reconocimientos e informes, que obran en dicho expediente, dados por los maestros de obras y demás peritos a el efecto; por lo que estando bien cerciorado en los expresados puntos, y cotejado el plano con la propia obra, le encuentro estar conforme a ella, y a la configuración, que tienen los tres ramos de mina, así la Maestra Inferior, como las dos superiores de la disputa, que la domina en quince pies de altura, como de / 4v. muestran las letras A-J y B- $\mathrm{n}^{\circ} 6$, y habiendo medido la profundidad del cubo, y altura que forma la presa en la canal $\mathrm{n}^{\circ} 7$, sobre la perpendicular de dichos cubos, le encuentra muy escasa para que pueda imponer a la maquina la debida violencia a su utilidad, a que se le agrega la desigualdad que tiene el petril que forma la presa o canal $\mathrm{n}^{\circ} 7 \ldots 7$, y el faltarle a este tres pulgadas de altura, para estar en el ser y estado, que ha estado siempre, según la demarcación que en el existe; por lo que hace a la contradicción absoluta, que el Fiscal encuentra entre los dos peritos don Cayetano Vélez y don Manuel Zintora, [sic] no se advierte en sus declaraciones cosa alguna mas que la equivocación que se padeció en la visita general, folio 12 y 13, por lo intempestiva y pronta de sus conocimientos, que carecían de las precisas y oportunas operaciones a el efecto, como lo confiesa después el mismo perito, folio 67, vuelta cuya equivocación primera, no debe tenerse en un facultativo por contradictorio, y quando [sic] no se está cerciorado en una materia, ni 
tampoco debe tenerse por implicado la diversidad de nombres facultativos de que usa el otro, en los cuerpos respectivos y operaciones, por las voces que manifiesta en sus diversas diligencias y declaraciones; de forma que estan conformes, y en un mismo dictamen los dos expresados peritos, y por consiguiente la obra arreglada a arte o reglas hidráulicas, y sin causar el más leve perjuicio a las aguas en que estas puedan huir o filtrarse a otra parte alguna por la disposición que estan los terrenos adyacentes, y por el corto remanso, qual [sic] forma la presa sobre los cubos, cuya tendencia no alcanza / 5r. A más en las citadas minas, que a nueve o diez varas de longitud, habiendo hasta el boquete de los nacimientos otra tanta distancia o más según la rapidez con que bajan las aguas, estas no pueden tener mas filtración, que a la Mina Maestra que está debajo en caso de tenerla, siendo un imposible de que el citado molino ni otro cualquiera de su clase, pudiera moler con agua corriente sin la competente represa, que forma la columna de agua que es quien hace la de imponer a la máquina la rapidez necesaria, pues es tan corto el peso que tiene el de la disputa, que no alcanza a igualarse con la Hacienda, que haga una arreglada atahona, pero teniendo el saetillo de dicho molino dos pulgadas de latitud , y dos y media de longitud, arroja toda el agua que producen dichas dos minas, por lo que nada perjudicial es que haya el remanso de agua, que hay sobre dichos cubos, y presa mediante arrojar dicho saetillo, y atajea subterránea, que corre por bajo del plan de dichos asientos sobre las aguas de la Mina Maestra que se dirige a esta ciudad para su abasto público la misma cantidad de agua que arrojan los nacimientos de dichas dos minas superiores sin que estos puedan ser mas abundantes y copiosos, no teniendo el impedimento que se dice de dicho molino, ni tampoco en nada le es perjudicial el que tenga dos asientos o piedras, porque le sería nocivo a dichas aguas, de que no molieran ambas a un mismo tiempo, en caso de haber suficiente cantidad para ello, porque más porción caería sobre la citada mina maestra, pero es el caso contrario, que aunque hay dos piedras, no puede moler mas que una, y con corta rapidez, / $5 \mathrm{v}$. De forma que dándole agua a las dos, en quince o diez y seis minutos se paran ambas, como se ha hecho ver por uno de los varios experimentos, ejecutados en el acto de la diligencia por manera que habiendo practicado todos los precisos experimentos, y tomados los conocimientos necesarios, debe ponerse el petril de la canal, con el preciso arreglo, y en el ser y estado que antes estaba, subiéndole las tres pulgadas que le falta, y arreglándolo a que en el caso de rebosar las aguas de dicha presa o canales derrame sobre la citada Mina Maestra, por vera del tablón de su desagüe, y no inutilice el pavimento de dichos asientos, y las harinas que en ello haya, que es quanto [sic] debe manifestar en el prenotado asunto. Sevilla 9 de febrero de 1820. Echamoros $^{21}$.

José Echamoros es un arquitecto contrastado y reconocido en el municipio sevillano cuando se le requiere para que emita este informe de las obras del molino de la Mina. Se le debe posiblemente la nueva Puerta de San Fernando a fines del siglo XVIII junto a la Real Fábrica de Tabacos. También la reforma de la Puerta de la Macarena en 1795 y los proyectos para la puerta de Córdoba en Carmona en 1796

21 AHNOBLEZA. FERNANNUÑEZ, C. 69, D. 17, fol. 4v-6r. 
(Arenillas, 2000, pp. 110, 119). Así como las reformas en la Plaza del Pan en 1821 y el proyecto de alineación de calles desde la Plaza de la Encarnación hasta Francos por sugerencia directa de los síndicos municipales (Ollero, 2015, pp. 215, 257). En torno a 1812, realiza un informe sobre el estado en que había quedado la Cartuja de las Cuevas tras la presencia francesa en el monasterio (Martínez, 1995, pp. 137, 149). José Echamoros presenta este informe detallando algunas modificaciones importantes que debían realizarse en el molino de la Mina para que funcionara correctamente. Además, durante estas primeras décadas del siglo XIX los arquitectos titulares revindicarán un protagonismo único en la aprobación de los diseños, de modo que solicitan que los cargos gremiales no comparezcan al acto de la dación de medidas (Ollero, 2005, pp. 113, 123). Su comparecencia en el molino no sólo se limita al acto de dar las medidas, Echamoros se caracteriza por estar vinculado de manera directa con el fenómeno academicista, en el cual se alude al carácter distintivo de su formación al mencionar sus conocimientos teóricos o matemáticos (Ollero, 2012, pp. 27, 42). Por este razonamiento, realizó primero la medida de la profundidad y altura del cubo continuando con la altura de la represa del canal. Confirmando con estas mediciones que estaba muy habituado al uso de libros que aportaban al arquitecto consejos técnicos sobre como proceder y afrontar problemas constructivos dando las soluciones prácticas para este molino hidráulico. Echamoros conocía bien la obra de Juanelo Turriano y se constatan datos de este libro que están recogidos en este informe, por ejemplo, las medidas de los saetillos ${ }^{22}$. Hay que tener en cuenta que esta obra está hoy considerada mundialmente como el primer tratado de hidráulica (Sánchez, 2015, p. 65). Con estos cálculos matemáticos Echamoros calculó la capacidad de los cubos y supo que debía levantar tres pulgadas la represa para alcanzar la máxima cota de desnivel posible y lograr el peso necesario que ponía en marcha todo el mecanismo de la molienda. La hidráulica era una materia considerada como de necesidad absoluta dentro del saber matemático, hay que recordar que sin geometría ni aritmética es imposible replantear correctamente, cubicar piezas, medir y tasar con precisión, ajustar las cuentas en obra (Irisarri, 2015, p. 199). Estos cubos estaban realizados con sillería o mampostería y con un enfoscado interior para evitar pérdidas de agua llegando a ser su altura mínima recomendada en los diferentes tratados de cuatro metros (López, 2006, p. 63). La medida de los cubos era muy importante porque se ganaba energía potencial que se transformaba en energía cinética necesaria para mover el rodezno, permitiendo utilizar menores caudales de agua y lograr la misma potencia. Echamoros incluye en este informe la modificación del saetillo y da unas medidas exactas para conseguir mayor rendimiento. Este artilugio era una pieza que se colocaba al final del cubo y tenía forma tronco-piramidal y era por donde salía el chorro de agua dirigida con la

22 También estudiaría dos obras clásicas como "Las diversas y artificiosas máquinas del capitán Agostino Ramelli de Ponte Tresa”, este libro constituye una obra clásica de la ingeniería del renacimiento, y el "Trattato di architectura e machine" de Francesco di Giorgio en que se explica de forma teórica los principios de las máquinas hidráulicas. 
máxima presión posible hacia los álabes del rodezno. Éste generaba un movimiento circular que era transmitido mediante un eje vertical de hierro a la piedra volandera, lo que permitía lograr la misma potencia empleando menores caudales (González, 1992, p. 191). Asimismo, Echamoros realizó las comprobaciones y pruebas necesarias para poner en funcionamiento las dos piedras del molino como pretendía el mencionado Juan Calzado. Con este ensayo práctico comprobó que el funcionamiento de las dos piedras duraba sólo 15 o 16 minutos y se paraban por falta de caudal, recomendando por ello el uso de una sola piedra. Por último, hay un detalle en el informe que no debemos dejar pasar, es cuando dice que la obra de este molino debe "arreglarse al arte o reglas hidráulicas", con este dato podemos afirmar que conocía la obra de Turriano detalladamente. Echamoros es un hombre de una amplia formación lo que le permitió dar soluciones a problemas concretos. También, y como apunta el profesor Suárez Garmendia, se pone de manifiesto en este informe que José Echamoros y Cayetano Vélez no se profesaron una buena amistad, sino todo lo contrario (Suárez, 1986, p. 45). Esta controversia venía desde que Echamoros inició un pleito que va a durar hasta 1819 y durante el cual se demostró que Vélez en el momento del nombramiento no era arquitecto titulado. En base a ello la Real Audiencia anuló el nombramiento por sentencia de 14 de julio de 1818 y el municipio volvió a nombrar a Echamoros en 1819 (Baena, 2015, p. 508). También, la intervención sobre el mercado de abastos de la Encarnación fue motivo de conflicto entre ellos (Ollero, 2006, pp. 81, 94). Cayetano Vélez no obtuvo tal reconocimiento oficial por la Academia hasta 1818 (Ollero, 2015, pp. 215, 257). En cambio, Echamoros si colaboró con Manuel Cintora en 1819 en la restauración que realizó en la portada de la Casa de la Moneda (Falcón, 1994, p. 347).

Para finalizar, quisiera resaltar que actualmente no conocemos fuentes bibliográficas en la que se mencionen informes emitidos por Vélez, Cintora y Echamoros en relación a molinos hidráulicos de agua. Sólo se menciona a Echamoros en las reparaciones de los husillos del cabildo municipal sevillano (Velázquez, 1860, p. 70), y en las labores que realizó de infraestructuras en las alcantarillas de la Torre del Oro y San Bernardo (Suárez, 1987, p. 260). También emitió un informe en 1808 al Ayuntamiento sobre reparaciones en los Caños de Carmona, la Cañería Nueva y fuentes públicas que perdían grandes cantidades de agua potable por el recorrido (Baena, 2015, p. 225). Sobre Cayetano Vélez conocemos que emitió un informe al Ayuntamiento sobre la situación de las fuentes públicas de la ciudad en 1809 y otro informe de 1811 sobre las obras de reparación necesarias en los Caños de Carmona por un valor de 1.300 reales (Baena, 2015, pp. 226, 228).

\section{GLOSARIO}

Álabes: es una paleta curva de una máquina hidráulica que desvía el flujo de agua para intercambiar la cantidad de movimiento del agua con un momento de fuerza en el eje. 
Atarjea: canal por donde discurre el agua y que la transporta hasta el molino.

Canal: es por donde viene el agua a los cubos y por donde luego desaguará.

Cubo: es donde se deposita el agua que cae del canal. Es un gran tubo cuyas medidas oscilan en función del caudal de agua. El agua al precipitarse por el interior del cubo cae con fuerza y es la que se aprovecha para hacer mover al molino.

Energía hidráulica: es aquella fuerza motriz natural del agua capaz de convertir la energía potencial durante la caída en energía cinética.

Piedra de molino: son las piedras encargadas de triturar el cereal. Son dos piedras colocadas en horizontal, una encima de la otra. La piedra de abajo suele ser fija y la de arriba (piedra volandera) es la que se mueve y gira.

Piedra volandera: es la piedra móvil por ella se vertía el grano por un agujero central y el polvo molido (harina) salía por los bordes donde se recogía.

Pretil: muro protector construido para preservar la caída de agua.

Represa: obra que se lleva a cabo para contener o regular el curso del agua.

Rodezno: es una rueda (turbina) que en todo su diámetro tiene una serie de cucharas denominadas álabes. Sobre estos álabes sujetos a la rueda cae el agua desde el saetillo y hace girar la rueda y acciona con ello el molino.

Saetillo: el agua que se recoge en el cubo pasa a través de un estrecho orificio llamado saetillo que hace aumentar la presión del agua que incide sobre los álabes del rodezno.

\section{BIBLIOGRAFÍA}

Aguilar Piñal, Francisco (2002). El señor del Gran Poder. Un granadino dueño de Sevilla. Sevilla: Universidad de Sevilla.

Álvarez Nogal, Carlos (2000). Sevilla y la Monarquía Hispánica en el siglo XVII. Sevilla: Ayuntamiento de Sevilla.

Aparicio Carrillo, María Dolores [et al.] (1990). El agua en Sevilla. Sevilla: Guadalquivir.

Arenillas Torrejón, Juan Antonio (2000). Conservando un símbolo: Tres siglos en la historia de la Puerta de Córdoba. Sevilla: Centro de documentación de IAPH.

Baena Gallé, José Manuel (2015). Sevilla (1808-1814): Guerra y Cultura. Tesis doctoral. Sevilla: Universidad de Sevilla.

Bernal, Antonio Miguel (2003). "Industrialización rural, industrias agroalimentarias y crecimiento económico: la agroindustria molinero-panadera en la campiña sevillana (SS. XV-XX)". En: Las industrias agroalimentarias en Italia y España durante los siglos XIX y XX. Alicante: Universidad de Alicante. 
Bernal, Antonio Miguel (2003). Estudio de la industria panadera de Alcalá de Guadaíra. Alcalá de Guadaíra (Sevilla): Ayuntamiento de Alcalá de Guadaíra.

Falcón Márquez, Teodoro (1994). "La arquitectura en la Baja Andalucía". En: El Arte del Barroco. Historia del Arte en Andalucía. Sevilla: Ediciones Gever.

Fernández Chávez, Manuel Francisco (2011). Los Caños de Carmona y el abastecimiento de agua en la ciudad moderna. Sevilla: EMASESA.

Flores, Leandro José de (1833). Memorias históricas de la villa de Alcalá de Guadaíra, desde sus primeros pobladores hasta la conquista y repartimiento por San Fernando. Sevilla: Imprenta de Mariano Caro.

González Tascón, Ignacio (1992). Fábricas hidráulicas españolas. Madrid: Centro de Estudios y Experimentación de Obras Públicas.

Irisarri Martínez, Carlos Javier (2015). El arquitecto ilustrado: del oficio a la profesión. Consolidación del modelo contemporáneo del arquitecto español en el siglo XVIII. Tesis doctoral. Madrid: Universidad Europea de Madrid.

López García, Rafael (2006). Molinos hidráulicos: apuntes de historia y tecnología. Alcalá la Real (Jaén): Alcalá Grupo Editor.

López-Vidriero, María Luisa (1999). Los libros de Francisco de Bruna en el Palacio del Rey. Sevilla: Fundación Cajasol.

Márquez Redondo, Ana Gloria (2010). Los Alcaides del Alcázar de Sevilla. Sevilla: Patronato del Real Alcázar.

Márquez Redondo, Ana Gloria (2010). El Ayuntamiento de Sevilla en el siglo XVIII. Sevilla: Ayuntamiento de Sevilla.

Martínez Montiel, Luís Francisco (1995). De monasterio a cuartel: la fortificación de la Cartuja de Sevilla durante la Guerra de la Independencia. Archivo Hispalense, $\mathrm{n}$. 234, pp. 137-149.

Ollero Lobato, Francisco (2002). La ocupación francesa de Sevilla y la difusión del Neoclasicismo: La decoración de la casa de los Cavaleri. Laboratorio de Arte, $\mathrm{n}$. 15, pp. 189-199.

Ollero Lobato, Francisco (2004). Cultura artística y arquitectura en la Sevilla de la Ilustración (1775-1808). Sevilla: Caja San Fernando.

Ollero Lobato, Francisco (2005). Arquitectura doméstica en Sevilla durante la segunda mitad del siglo XVIII. Atrio, n. 10/11, pp. 113-123.

Ollero Lobato, Francisco (2006). La Sevilla soñada. Plazas y ciudad en los inicios del siglo XIX. Atrio, n.12, pp. 81-94.

Ollero Lobato, Francisco (2012). La maestría mayor de obras de la Real Audiencia de Sevilla (siglos XVII-XIX). Atrio, n. 18, pp. 27-42.

Ollero Lobato, Francisco (2015). Ciudad e Ilustración. Transformaciones urbanas en Sevilla (1767-1823). Cuadernos dieciochistas, n. 16, pp. 215-257. 
Obras en el molino de la Mina de la villa de Alcalá ... - Fernando García Sánchez

Ollero Lobato, Francisco (2016). Dos diseños de arquitectura efímera de Cayetano Vélez para las casas capitulares de Sevilla. Laboratorio de Arte, n. 28, pp. 387-400.

Ros González, Francisco (2000). El retablo mayor de estuco de la parroquia de Omnium Sanctorum de Sevilla. Laboratorio de Arte, n. 13, pp. 153-172.

Sánchez Jiménez, Francisco Javier (2015). Estudio histórico-técnico de los molinos hidráulicos de Alcalá de Guadaíra. Tesis doctoral. Sevilla: Universidad de Sevilla.

Suárez Garmendia, José Manuel (1986). Arquitectura y urbanismo en la Sevilla del Siglo $X I X$. Sevilla: Diputación Provincial de Sevilla.

Suárez Garmendia, José Manuel (1987). El urbanismo en Sevilla en el siglo XIX. Sevilla: Diputación Provincial de Sevilla.

Turriano, Juanelo (1982). Los Veintiún libros de los ingenios y de las máquinas. Madrid: Fundación Juanelo Turriano.

Velázquez y Sánchez, José (1860). Archivo Municipal de Sevilla: Siglo XIX. Segunda época Constitucional (1820-1823). T.16, N.70. Sevilla: Ayuntamiento de Sevilla.

Vila Vilar, Enriqueta (2016). El Consulado de Sevilla de Mercaderes a Indias. Un órgano de poder. Sevilla: Ayuntamiento de Sevilla. 